\title{
Wedding Night
}

\section{Yehudis Fletcher*}

*Correspondence: yfletcher@gmail.com

\section{Covered}

Wrapped in white

My mother

led me to the chuppa

That night

the light

was switched off when we were alone

(c) Copyright: The Authors. This article is issued under the terms of the Creative Commons Attribution Non-

Commercial Share Alike License, which permits use and redistribution of the work provided that the original author and source are credited, the work is not used for commercial purposes and that any derivative works are made available under the same license terms.

Five times he unwrapped me

That first night

Afterwards,

there was light outside

But inside

Like a toy with a broken spring

I was pushed down, again and again

I didn't bleed,

Someone else had done that to me 
So with light outside, and seeing as I was still pure

I was again

Unwrapped

My skin

wore thin

there was nothing left

Finally

red blood fell

It made me impure

And I was untouchable

Later

On the doctor's couch

He said I was just torn

Still pure

After all.

Those were the first times

The last time was

more than a decade later

I finally said no

I cried and said no 
Explanatory Note: In orthodox Judaism, menstrual bleeding renders a woman 'impure', and means that sexual contact is forbidden. Some also follow the 'tradition' of categorising a so-called virgin bride bleeding from a ruptured hymen in the same way. Genital bleeding from any other injury does not render a woman 'impure'.

Yehudis Fletcher is the founder of Nahamu, a think tank countering extremism in the Jewish community and an Independent Sexual Violence Adviser for Migdal Emunah. She is a student of Social Policy at Salford University.

\section{To cite this poem:}

Fletcher, Y. (2020) 'Wedding Night', Feminist Dissent, (5), 132-134.

Retrieved from: https://doi.org/10.31273/fd.n5.2020.761 